\title{
LIMITS TO PROFITABILITY OF AUTOMATED MASONARY
}

Drees, G. Laukemper, J.

Pritschow, G. Dalacker, M.
- Institute of Construction Management

University of Stuttgart

Pfaffenwaldring 7

D - 7000 Stuttgart 80

Germany

- Institute for Control Technology of Machine Tools and Manufacturing Systems

University of Stuttgart

Seidenstraße 36

D - 7000 Stuttgart 1

Germany

\section{SUMMARY}

Apart from production costs, the saleability of the finished product and the acceptance of the new technology by construction industry are decisive factors for making automation in construction profitable. To achieve this goal, organisation and logistics are to be in line with construction environment. With al1 these requirements met, chances for automating masonry are good. A robot at a price of 430,000 DM, used for automatic masonry on the site, is profitable when reaching a depositing time of 40 secs per stone. Moreover, if one refers to solutions existing in the manufacturing industry, an automation of masonry seems very promising.

\section{Introduction}

Masonry is a field of construction offering a big potential for automation. Masonry consists of work that can easily be subdivided into steps like grabbing, transporting and depositing of bricks, and spreading of mortar, which further enhances its chances for successful automation. Other contributions on this topic, both in recent years and this year, have come to the same conclusion.

To be successfully introduced into construction work, automation, apart from meeting both social requirements and such related to the protection of health, is required to prove profitable. This demand for profitability is not restricted to production costs but extends to the following:

- the product must be in line with market conditions, i.e. saleable,

- costs of production must be lower than those of manual fabrication,

- organisation and logistics must be in line with the working environment in construction firms and on sites,

- the technology used should be universally applicable and adapted to building conditions.

Masonry offers two possibilities: that of industrial prefabrication or of automatic fabrication on the floor by means of mobile masonry robots. In the following, for reasons explained in [2], only the latter possibility is discussed in detail. 


\section{CHARACTERISTICS OF MASONRY IN GERMANY}

Masonry is mainly used in housing. In $1988,88.6 \%$ of all building permits granted for housing were masonry, the rate for other buildings was only $51.8 \%$. Two-thirds of all flats built in 1989 are in buildings containing only one or two flats [1]. In general, houses are built in brickwork with load-bearing walls and do not, as in other countries, have a reinforced concrete skeleton structure where brickwork merely serves to close a room or for an infill. Even non-bearing walls that mostly serve to close a room are often built in nonbearing brickwork. The thickness of bearing walls is $36.5 \mathrm{~cm}, 30 \mathrm{~cm}, 24 \mathrm{~cm}$ or $17.5 \mathrm{~cm}$, that of non-bearing walls $17.5 \mathrm{~cm}$ or 1 ess.

In 1988, the total production of bricks was 17.7 million $\mathrm{m}^{3}$ for 208,600 newly-built flats ${ }^{2}$. Due to higher expectations, the immigration from the east and the long suppressed demands of the inhabitants of the former German Democratic Republic (GDR), the building of at least 200,000 - 250,000 flats per year is to be expected in the Federal Republic of Germany of today in the next ten years.

As the rate of masonry buildings in comparison with all flats to be built is $88.6 \%$, this amounts to 177,000 flats. Based on an average of approximately $60 \mathrm{~m}^{3}$ of bricks required for one flat, a total of $10.6 \mathrm{mill}^{\mathrm{i}} \mathrm{on} \mathrm{m}^{3}$ of bricks is needed. On the assumption that only $60 \%$ of the masonry to be built are suitable for automation, there are still 6.4 million $\mathrm{m}^{3}$ to be built by robots, i.e. there is a big enough market for the development of a robot.

\section{SALEABILITY}

The plans of houses or blocks of flats often show a very individual design which is reflected in varying room sizes, partly skew-angled connecting walls and walls with a curved plan.

Cheap houses with a low standard are more suitable for automated production but would probably not find a market in Germany. In order to achieve the required flexibility, building systems either need to have a very small grid unit or be composed of a variety of special elements. None is suitable for automation. Bricks meet all the requirements for flexibility. With them it is possible to use large-sized stones that can easily be cut to the right size on the site which reduces the number of different bricks needed on a site. Stock bricks, sand-1ime bricks and cellular concrete bricks are the preferred material.

Solutions from other countries are developed for the respective conditions there and can not easily be adapted to those in Germany. Reinforced formwork blocks for reinforced concrete walls is one example: this system does not meet the requirement of flexibility, unless a large number of special elements is used which are very expensive to produce. What makes this method even more costly than masonry is the fact that the reinforced concrete wall is to be filled with concrete. The wall itself is not in accordance with the prescribed value for heat insulation and needs an expensive insulation cladding. In addition, houses with the former GDR. 
reinforced concrete walls are difficult to sell. This serves to illustrate how important the respective market conditions are for a study of profitability.

\section{NECESSARY RESTRICTIONS FOR AN AUTOMATION OF MASONRY}

It is advisable to use existing building systems, masonry in this case, that can be adapted to automation, when necessary, if a short-term realisation of automatic fabrication is to be achieved. For the following reasons completely new building system should not be used:

- The development and introduction of a new building system specifically designed for automation will extend over a long period of time.

- Building investments are long-term investments, especially where housing is concerned. No-one will be inclined to use an unknown building system that has not yet proved worthwhile over a longer period.

- Building systems force the planner to subordinate his ideas to the requirements of the system.

- A couple of building systems praised in the past, e.g. the slab method, have proved worthless and been discredited.

Considering the diversity of masonry buildings, it would not be possible technically or be unprofitable to automate all masonry work. Sensible restrictions are required:

- Curved walls, either in plan or in elevation, like arches, can not be automated, because it is hardly possible to join stones that do not meet at a vertical angle. As these elements seldom occur $(0-10 \%)$ they may be complemented manualiy.

- Fair faced bricks are to be checked for injuries and should be uniform in size and shape which, in conjunction with the small size of the stones, makes facework unsuitable and unprofitable for automation.

- By using large-sized stones, thin non-bearing internal walls may be built manually which makes automation unprofitable.

- Due to its much simpler robot technology (refer to [4]), the only method applicable to an automation of construction sites is that of dipping the bricks into thin seam mortar, just as it has been tried in [5].

\section{OTHER PREQUISITES FOR AUTOMATION}

A profitable automation may be achieved only if it is strictly adapted to site conditions or even improves them. The following aspects are to be considered:

- Taking into account stock load caused by stones, the weight of a robot must be less than $1,000 \mathrm{~kg}$, or even less for some buildings; otherwise, additional reinforcements or ceiling supports are necessary.

- With more than $60 \%$ of flats being in buildings containing only one or two flats, the effort for the installation of the robot should be kept as small as possible, as it is likely to be moved almost daily from one site to the next. 
- The robot should be of small size to be able to move around in buildings with a complex plan and to fit through door openings. It is impossible, in general, to use separate robots for unloading and depositing stones (refer to [5]) with internal walls.

- Another problem, especially occurring in connection with mobile, programmable robots, with the movements of their arms added to that of the robot itself, is safety. The staff on a site is far from experienced in dealing with robots and is therefore very endangered.

- Logistics is to be kept simple. It would be very convenient if the stones were delivered on pallets from where they could be grabbed directly and if the same stones could be used for manual complements. This restricts the weight of the stone to $25 \mathrm{~kg}$.

- Deviations in tolerance exceeding those allowed for evenness and length of a floor are to be corrected. Even in this case automatic production must be possible.

A possible scenario for automatic production on the site is shown in figure 1. Prior to the beginning of the actual work the dimensions are measured, the walls are arranged in stones by means of a simulation program and the cut stones cut to the right sizes. A robot working from a fixed position grabs stones from pallets and builds wall-high segments that are stepped at one side. After having finished a segment the robot moves on to the next position.

The Institute for Construction Management and the Institute for Control Technology of Machine Tools and Manufacturing Systems have joined for further research on this topic in order to evaluate and solve the technical problems involved.

\section{PRODUCTION COSTS}

For obvious reasons, it has not been possible to refer to practical experiences to estimate costs and performance of a masonry robot. To get a general idea of a robot's profitability, the parameters having an influence on that profitability have been varied.

The profitability of automatic fabrication has been compared to that of an optimum manual fabrication (smallest possible effort, as described in [7]), as probably mostly those innovative companies will make use of robots that have already exhausted other methods of rationalisation. Only labour costs (cost of wages and equipment) have been compared, not the costs for each work component.

Costs for automatic masonry may be broken down as follows:

- costs of equipment: depreciation (5 years) + interest + reinstatement ( $10 \%$ of the value when new) of the robot, the hauling vehicle and its trailer

- other costs: energy cost of the robot, tax, insurance and fuel for the hauling vehicle, data input

- wage costs: wage costs for the operator plus a $20 \%$ bonus on the robot's operating hours for trouble-shooting or other work. 
Costs for brickwork depend on the size and weight of the stones and on the object size. This applies both to manual and automatic fabrication. The stone size for manual fabrication is determined by the minimum time needed for depositing 1 cubic metre of stones, for automatic fabrication by the bearing capacity of the robot, which is to be restricted to $25 \mathrm{~kg}$.

Another factor having influence on performance where automatic fabrication is concerned is the number of stones and the cut stones per cubic metre of brickwork. In order to find out the exact number of stones needed for a building, automatic brickwork for different buildings with different wall thickness and stone length has been simulated by a program developed at the Institute of Construction Engineering [4].

The following paramters have been varied:

- operating hours

- depositing time per stone

- investment costs for the robot

- wall thickness of external/internal wall in $\mathrm{mm}$

\author{
$800 h-2,200 h$ \\ $30 \mathrm{sec}-60 \mathrm{sec}$ \\ $300,000 \mathrm{DM}-500,000 \mathrm{DM}$ \\ $365 / 240,300 / 240,300 / 175,240 / 175$
}

In the case of manual fabrication, a variation of the wall thickness has a strong influence on the cost per cubic metre of masonry. There have been differences of $15 \%$. This is not a problem with automatic fabrication where thinner walls simply result in the use of longer stones so that the number of stones per cubic metre and thus the time and cost for depositing remain even. There have been differences of only 1 or $2 \%$. The cost development shown in figures 2 and 3 refers to the worst possible case of $30 \mathrm{~cm}$ external walls and $17.5 \mathrm{~cm}$ internal walls.

A masonry robot should be in use at least 1,200 operating hours per year. If operating 8 hours a day, which corresponds to 10 working hours for the operator, the robot is operating 150 days annually, a work that can still be accomplished by only one operator. In order to offer more incentives to invest, the highest cost acceptable for automation should not be set at the lowest cost for manual fabrication, but below it. The performance of a robot per operating hour amounts to $2.95 \mathrm{~m}^{3}$ at a depositing time of 30 secs, $2.20 \mathrm{~m}^{3}$ at 40 secs, $1.85 \mathrm{~m}^{3}$ at 50 secs. This refers to mixed masonry. The acceptable price for a robot with a depositing time of $40 \mathrm{secs}$, for example, amounts to approximately 430,000 DM.

The potential for rationalisation is even higher than shown in figures 2 and 3 , if one considers that the stones in use today are still mostly smal1sized.

\section{SOME REFLECTIONS ON THE TECHNICAL REALIZATION OF A MASONRY TASKING ROBOT}

A mobile robot offering the functionality described above consists of two essential components:

- a mobile platform allowing movements all about the floor of a storey and

- a manipulator built upon the platform which performs the bricklaying itself. 
Considering the narrowness on construction sites and the need of high flexibility of the robot, a mobile platform has to be employed which allows freeranging movement througout the floor. Solutions based on stationary installations, e.g. rail-borne vehicles or Automated Guided Vehicles (AGV's) with guide lines buried into the floor (which are well-known form applications in production technology), do not meet these requirements. At the Institute for Control Technology of Machine Tools and Manufacturing Systems at Stuttgart, Germany, a prototype of a platform has been developed and constructed $[8,9]$, which meets the demands described above.

By using a modern navigation system and suitable sensors, distances of up to $20 \mathrm{~m}$ may be covered without using any physical guide 1 ine. Free programmability of the vehicle is assured. An adaptation of these navigation principles to the requirements of a construction site robot may easily be achieved.

Basically, for the mobile platform and the manipulator either electrical or hydraulic drives may be used. Their greater robustness under construction site conditions makes hydraulic drives the better choice. Another advantage is their higher power density, compared to electrical drives, i.e. less weight at a equal power rate. This is of great importance in respect of the strong restrictions concerning the weight of the robot (comp. chapter 5 ).

Disadvantages to hydraulic drives are the more complex control technology and the limitations regarding the attainable accuracy. These disadvantages, however, are not essential for brickstone handling, because there are no demands of high path accuracy: Exact positioning at the destination point is the crucial point.

Static deflections of the robot arms seem to be even more problematic. With a desired wall height of $3 \mathrm{~m}$, the total length of a robot arm amounts to $2,5 \mathrm{~m}$ [2]. Together with considerable stone weights (up to $25 \mathrm{~kg}$ ), static positioning errors at the end effector will be in the range of millimetres which is untolerable. Basically, such errors may be avoided by means of an integrated laser measurement system, as it is presented in [10], e.g.; Using photosensitive devices and laser beams which are guided within the robot arm, a very precise determination of static position deviations is possible. A correction may easily be done by methods of control technology.

For the application of spreading mortar to the stones there are two fundamental possiblities:

- active application, e.g. by means of a robot-guided mortar distributor or

- passive application, e.g. by dipping the stones into a tub filled with mortar.

The first version is more expensive in respect of instrumentation, whereas the second is limited to the use of thin seam mortar.

To ensure correct working of the robot and safety for the staff on the construction site, the implementation of several sensors is required. Their tasks may be classified as follows: 
1. Automatic recognizing and gripping of stones

Basically, a distinction is to be made whether the stones will be fed to the robot gripper system one at a time or whether they will be gripped directly form the pallet. In the second case, recognizing single stones by means of an optical sensor system such as a contour sensor will be suitable.

\section{Exact placing of the stones}

Because of unevitable sources of error within a construction site environment (rugged ground, measure tolerances, soiling) accuracy of stone positioning based upon indirect measurement systems such as incremental encoders is not sufficient. Therefore, the application of absolute measurement systems is indispensible. Laser measurement systems seem to be suited best.

\section{Protection of robot and operators}

The mobility of the masonry tasking robot presents an additional source of danger for the construction site staff. Reliable sensor systems must assure immediate system turn-off as soon as a person approaches the robot. Collision avoidance systems based upon ultrasonic sensors are low-priced and robust, but not always safe. More reliable but also more complicated are sensors which are capable of optically scanning a certain area around the vehicle and recognizing persons or objects entering this area.

As a whole, the sensor systems employed must be robust and fail-safe even under extreme construction site conditions (considerable soiling, high mechanical strain, weather factors). Complicated and sensitive components such as camera systems are not appropriate.

In the near future, fully automatic masonry construction is unlikely to be possible even when robots are employed. Modifications and completions of predefined masoning programms will still be necessary. For the programming system of the robot a user-friendly interface must be created which allows the required inputs. 
cross - section $\mathbf{A}-\mathbf{A}$ :

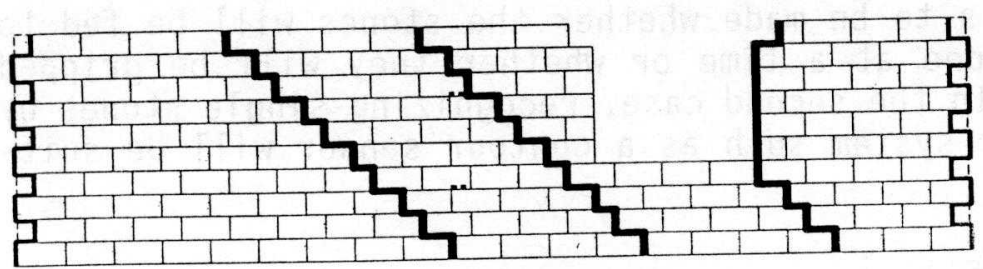

segment 3

segment 4 segment 5 segment 6

ground - plan:

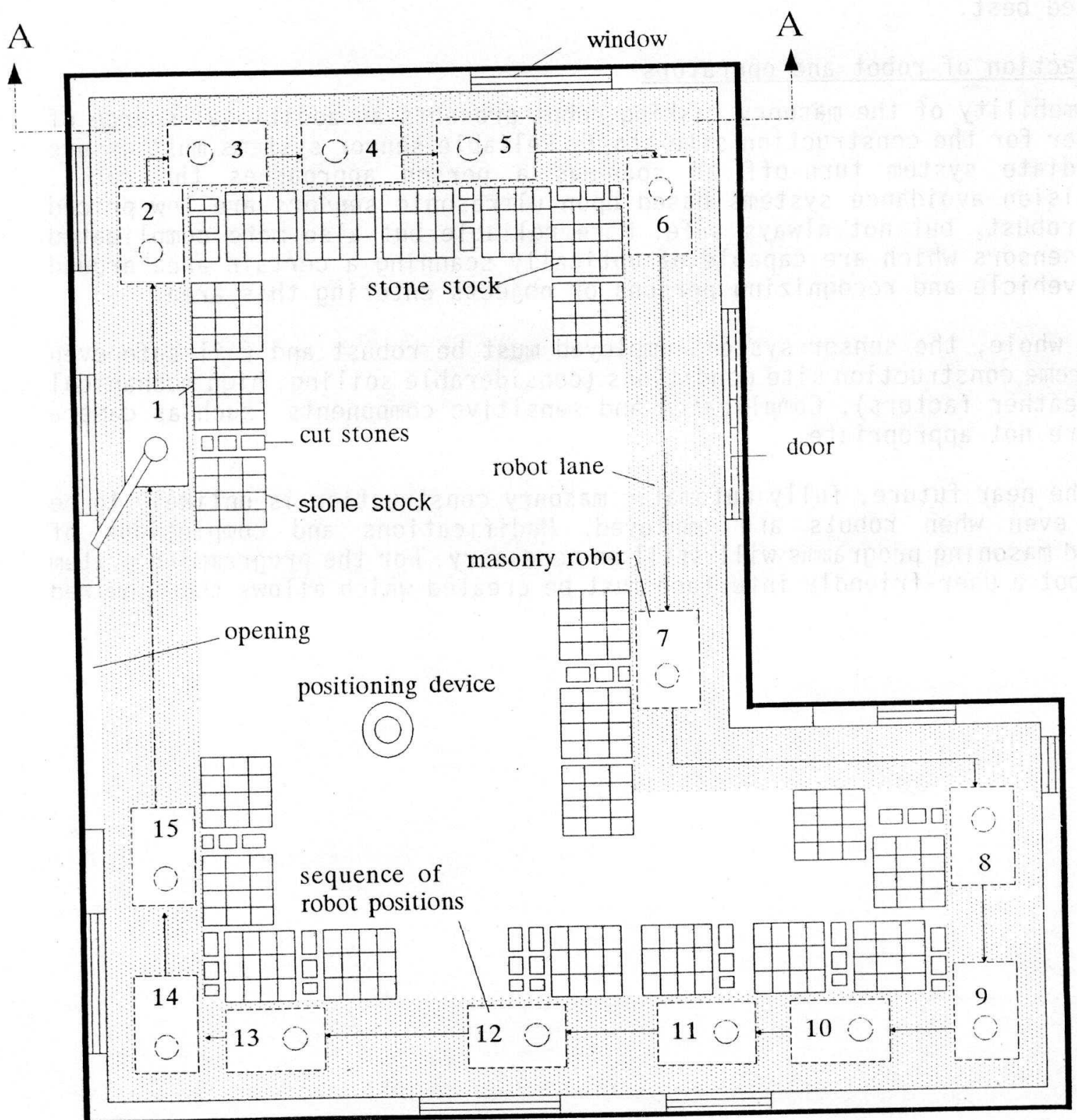

Figure 1: Flow chart for the erection of an external wall 


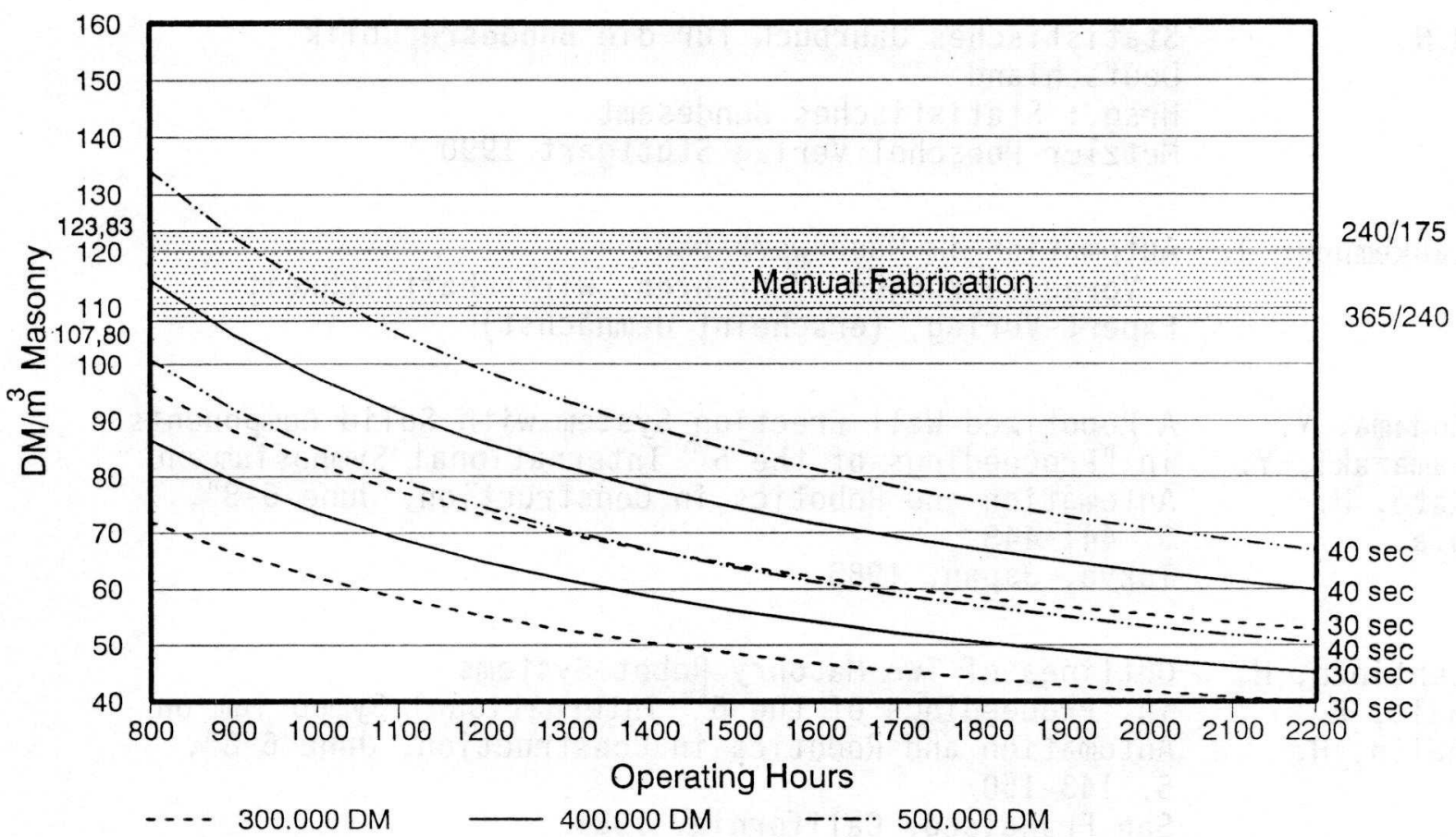

Figure 2: $\quad$ Profitability with a depositing time of 30 and 40 secs

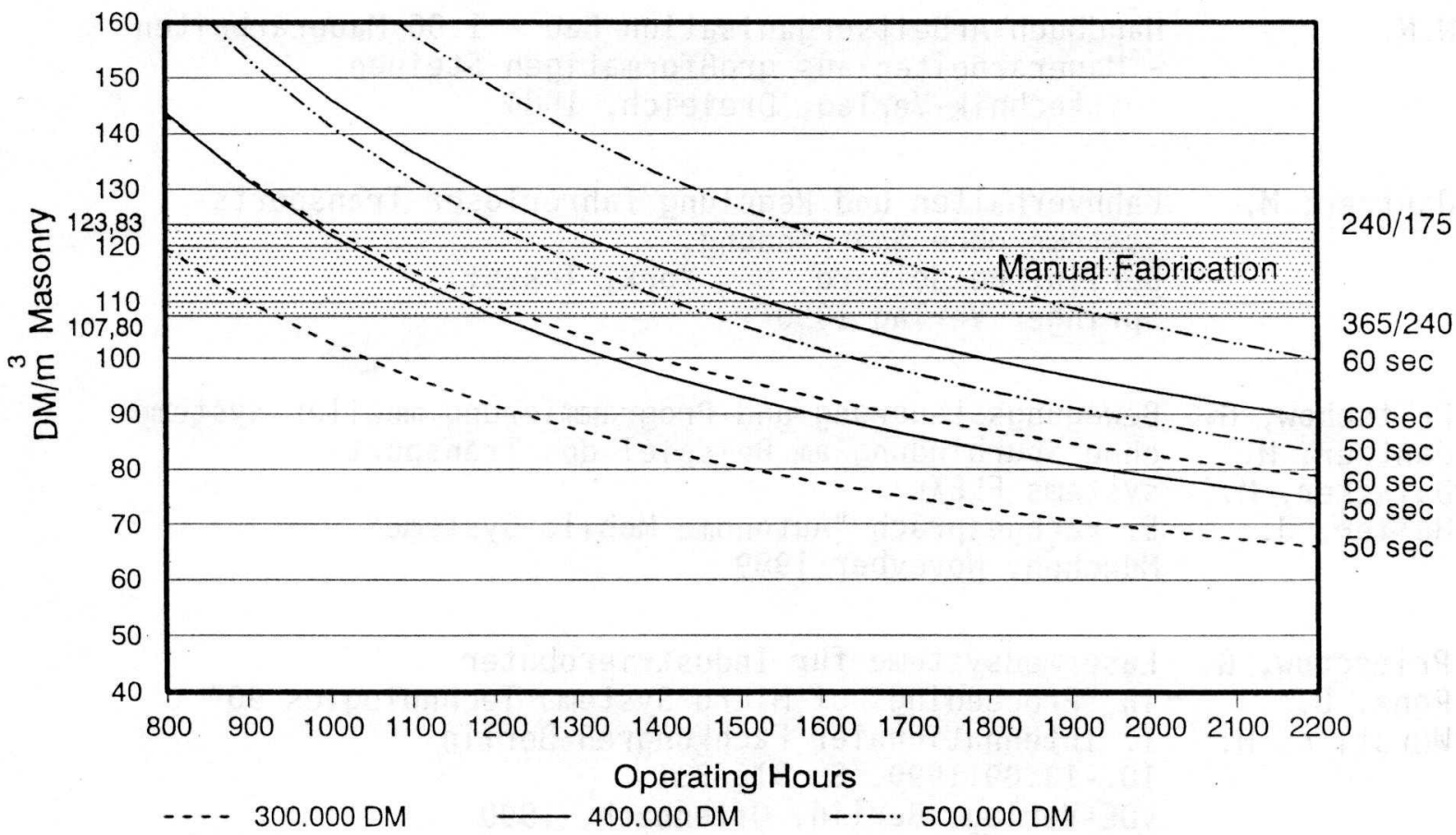

Figure 3: $\quad$ Profitability with a depositing time of 50 and 60 secs 
[1] N.N.

Statistisches Jahrbuch für die Bundesrepublik Deutschland

Hrsg.: Statistisches Bundesamt

Metzler-Poeschel Verlag Stuttgart 1990

[2] Laukemper, J. Automation im Mauerwerksbau

- Voraussetzungen, Verfahren, Wirtschaftlichkeit Expert-Verlag, (erscheint demnächst)

[3] Kodama, Y. A Robotized Wall Erection System with Solid Components Yamazaki, Y. in "Proceedings of the $5^{\text {th }}$ International Symposium on Kato, H. u.a. Automation and Robotics in Construction, June 6-8", S. $441-448$ Tokyo, Japan, 1988

[4] Lehtinen, H. Outlines of Two Masonry Robot Systems Salo, E. Aalto, H. in "Proceedings of the $6^{\text {th }}$ International Symposium on Automation and Robotics in Construction, June 6-8", S. $143-150$ San Francisco, California, 1989

[5] N.N. Baustatistisches Jahrbuch 1989 Verlag Graphia-Huss, Frankfurt, 1989

[6] Drees, G. Kalkulation von Baupreisen Bahner, A. Bauverlag, Wiesbaden, Berlin, 1988

[7] N.N. Handbuch Arbeitsorganisation Bau - 1.06 Mauerarbeiten - Mauerarbeiten aus großformatigen Steinen Zeittechnik-Verlag, Dreieich, 1984

[8] Jantzer, M. Bahnverhalten und Regelung fahrerloser Transportssysteme ohne Spurbindung Berlin, Heidelberg, New York, Tokyo: Springer Verlag 1990

[9] Pritschow, G. Bewegungssteuerung und Programmierung mobiler Systeme Jantzer, M. Dalacker, M. ohne Spurbindung am Beispiel des TransportHeller, J.: systems FLEXL 5. Fachgespräch "Autonome Mobile Systeme" München, Novevber 1989

[10] Pritschow, G. Lasermeßsysteme für Industrieroboter Renz, B. in "Proceedings of Micro Systems Technologies 90" Wurst 1 K. - H. 1. Intennationaler Fachkongre B Berlin 10. -13.09 .1990$, S. 316-331 VDE-Verlag, Berlin, Offenbach, 1990 